\title{
Injectional anthrax - new presentation of an old disease
}

T Berger (tamaritayberger@gmail.com)1,2, M Kassirer ${ }^{1}$, A A Aran ${ }^{1,3}$

1. Israel Defense Force, Medical Corps, Ramat-Gan, Israel

2. Department of Internal Medicine D, Rabin Medical Center, Beilinson Hospital, Petah-Tikva, Israel

3. Department of Pediatric Intensive Care, The Edmond and Lily Safra Children's Hospital, The Chaim Sheba Medical Center, TelHashomer, Ramat-Gan, Israel

Berger T, Kassirer M, Aran AA. Injectional anthrax - new presentation of an old disease. Euro Surveill. 2014;19(32):pii=20877. Available online: http://www. eurosurveillance.org/ViewArticle.aspx?Articleld=20877

Article submitted on 05 September 2013 / published on 14 August 2014

Bacillus anthracis infection (anthrax) has three distinct clinical presentations depending on the route of exposure: cutaneous, gastrointestinal and inhalational anthrax. Each of these can lead to secondary bacteraemia and anthrax meningitis. Since 2009, anthrax has emerged among heroin users in Europe, presenting a novel clinical manifestation, 'injectional anthrax', which has been attributed to contaminated heroin distributed throughout Europe; before 2009 only one case was reported. During 2012 and 2013, new cases of injectional anthrax were diagnosed in Denmark, France, Germany, and the United Kingdom. Here we present a comprehensive review of the literature and information derived from different reporting systems until 31 December 2013. Overall 70 confirmed cases were reported, with 26 fatalities (37\% case fatality rate).The latest two confirmed cases occurred in March 2013. Thirteen case reports have been published, describing 18 confirmed cases. Sixteen of these presented as a severe soft tissue infection that differed clinically from cutaneous anthrax, lacked the characteristic epidemiological history of animal contact and ten cases required complimentary surgical debridement. These unfamiliar characteristics have led to delays of three to 12 days in diagnosis, inadequate treatment and a high fatality rate. Clinicians' awareness of this recently described clinical entity is key for early and successful management of patients.

\section{Introduction}

Anthrax is a worldwide endemic zoonotic disease, particularly of herbivores, caused by the bacterium Bacillus anthracis, a Gram-positive rod. The infective form is usually the spore, a stable form that can survive in certain environments for decades [1]. Humans usually acquire anthrax infection by occupational exposure to contaminated animals or animal products such as hides, wool, hair and bones or by ingesting contaminated meat. The spores may infect the host through different routes and lead to a variety of clinical presentations depending on their route of entrance: cutaneous (the most common form of infection), gastrointestinal and inhalational anthrax. Complications of these three infections are secondary bacteraemia and anthrax meningitis. Once the spores have penetrated the skin or mucosa, they germinate to the vegetative bacteria, which proliferate and produce the virulence factors, two exotoxins - lethal toxin and edema toxin -, causing the characteristic pathological findings: edema, haemorrhage and tissue necrosis with a relative lack of leukocytes in infected tissues $[1,2]$.

Anthrax is a rare human infection in Europe and animal cases are sporadic and uncommon [3]. However, an outbreak of a fourth form of human anthrax infection, injectional anthrax, has been emerging among drug users in Europe since 2009 and has been attributed to contaminated heroin. Prior to 2009 only one case of injectional anthrax had been diagnosed, in Norway in 2000 [4]. The distribution of cases demonstrates a bimodal appearance of two clusters: over 100 cases were diagnosed between December 2009 and December 2010, the vast majority of them in Scotland [5-8], with no further cases documented until June 2012 when cases reemerged in England, Germany, Scotland and were diagnosed for the first time in Denmark, France and Wales $[9,10]$.

Injectional anthrax infection is unnatural and more severe than cutaneous anthrax infection, distinctive in its clinical presentation, course and management. This has resulted in a delay in diagnosis, inadequate treatment and high fatality rate among reported cases [8-11].

This comprehensive literature review of all injectional anthrax cases reported so far, aims to present an inclusive view of this novel clinical entity in order to improve clinicians' awareness and knowledge base.

\section{Search strategy and selection criteria}

References for this review were identified through searches of PubMed for articles published until 31 December 2013, by using the terms 'anthrax AND heroin', 'Bacillus anthracis AND heroin', 'Bacillus anthracis AND drug user', 'anthrax AND drug user' and 'injectional anthrax'. Articles resulting from these searches and relevant references cited in those articles were 
reviewed by TB starting with screening of abstracts followed by full text review where relevant. The Program for Monitoring Emerging Diseases (ProMED-mail) reporting system was searched by the terms 'anthrax AND heroin' until 31 December 2013 and by the term 'anthrax' from 1 December 2009 to 31 December 2013 and all relevant reports reviewed. ProMED-mail is an Internet-based reporting system, open to all sources, including media reports, official reports, online summaries, local observers, and other [10]. We also reviewed the Health Protection Scotland (HPS) 'National Anthrax Outbreak Control Team' report ('HPS report'), published in December 2011, on the anthrax outbreak among drug users in Scotland between December 2009 and December 2010 [8]. The European Centre for Disease Prevention and Control (ECDC) website [11] and Public Health England (PHE) website [9] were reviewed until 31 December, 2013. The ECDC website was searched for relevant information using the words 'anthrax AND heroin' and by reviewing the material published under the website heading Health Topic 'anthrax'. In addition, the ECDC's 2010-2013 annual epidemiological reports on communicable diseases in Europe were reviewed [11]. We searched the PHE website for the topic 'anthrax'. The findings under the topic were reviewed with the emphasis on information regarding the 2012-2013 outbreak. Articles, reports and data yielded by our search were included only if they were published in English.

\section{Results}

Overall 39 papers were retrieved through PubMed searches. Of those, 14 were not related to injectional anthrax and were excluded. Twenty five relevant papers, including references cited in these papers, were reviewed. Of those, 22 papers were included in the review and three papers excluded due to a lack of additional information.

A total of 70 laboratory-confirmed cases of injectional anthrax were reported among heroin users in Europe [4,6,8-11;14-26]. Apart from one case reported in the year 2000 , all cases were reported starting as of December 2009. Incidents appeared during two distinct time periods, forming a bimodal distribution (Figure).

The first and largest cluster of cases took place during 2009-2010 and consisted of 126 cases (54 laboratoryconfirmed cases, 35 probable cases and 37 possible cases). A majority of cases were recorded in Scotland. The main part of published data on injectional anthrax describe patients from this outbreak [6,8-11,16-22,24 ].

The second cluster of cases started with the reemergence of a total of 15 cases during June 2012 in six different European countries $[9-11,14,15,25,26]$. The last case was reported in Scotland in March 2013 [10]. Only few case reports regarding five confirmed cases exist concerning this second cluster of cases. Hence, the information regarding the number of cases, their geographical distribution and demographic description (if
TABLE 1

Number of laboratory-confirmed anthrax cases in drug users and fatalities among them by country, Europe, 2009 to $2013(n=69)$

\begin{tabular}{|l|c|c|c|c|}
\hline \multirow{2}{*}{} & \multicolumn{2}{|c|}{$\begin{array}{r}\text { December 2009- } \\
\text { December 2010 }\end{array}$} & \multicolumn{2}{|c|}{$\begin{array}{r}\text { January 2012- } \\
\text { December 2013 }\end{array}$} \\
\cline { 2 - 5 } & $\begin{array}{c}\text { Laboratory- } \\
\text { confirmed } \\
\text { cases }\end{array}$ & $\begin{array}{c}\text { Fatalities } \\
\text { (case- } \\
\text { fatality rate) }\end{array}$ & $\begin{array}{c}\text { Laboratory- } \\
\text { confirmed } \\
\text { cases }\end{array}$ & $\begin{array}{c}\text { Fatalities } \\
\text { (case-fatality } \\
\text { rate) }\end{array}$ \\
\hline Scotland & 47 & 13 & 2 & 1 \\
\hline England & 5 & 4 & 5 & 4 \\
\hline Germany & 2 & 1 & 4 & 1 \\
\hline Denmark & - & - & 2 & 1 \\
\hline France & - & - & 1 & - \\
\hline Wales & - & - & 1 & - \\
\hline Total & $\mathbf{5 4}$ & $\mathbf{1 8}(\mathbf{3 3} \%)$ & $\mathbf{1 5}$ & $\mathbf{7}(\mathbf{4 7} \%)$ \\
\hline
\end{tabular}

Source: $[8,10]$.

present) mainly relies on a review of the ProMED-mail, ECDC and PHE websites.

Course of events and epidemiological data Ringertz et al. were the first to coin the phrase 'injectional anthrax' in the year 2000. They described a confirmed case of anthrax in a 49 year-old, human immunodeficiency virus (HIV)-negative, heroin-injecting drug user in Norway [4]. The patient's exceptional presentation resembled the effect of subcutaneous inoculation of $B$. anthracis in chimpanzees and shared similarities with an old case report of possible transmission of anthrax by injection [4].

The following cases of confirmed 'injectional anthrax' were only reported in December 2009 among heroin users in Scotland and Germany [5-7], marking the start of the 2009-2010 injectional anthrax outbreak, that eventually included 126 cases (54 laboratory-confirmed cases, 35 probable cases and 37 possible cases) in Europe. The outbreak centered in Scotland with 119 cases: 47 laboratory-confirmed cases (13 fatal), 35 probable cases ( 1 fatal) and 37 possible cases. Case categories used by HPS are described in Table 2 [8].

Few cases were laboratory-confirmed in England (5 cases, 4 fatal) and Germany ( 2 cases, 1 fatal). The case fatality rate among confirmed cases was 33\% (Table 1). The vast majority of confirmed cases appeared between December 2009 and March 2010. The last case occurred in England in November 2010 (Figure 1). The outbreak was declared over in December 2010 and the HPS published its concluding report in December 2011 [8-11].

The average age of the 119 injectional anthrax cases in Scotland was 34 years (range 18-55 years), with more males than females in all case categories [8]. It appeared that all injection routes of heroin, as well as smoking or snorting had been implicated during the 
Timeline and geographical distribution of laboratory-confirmed injectional anthrax cases, Europe, December 2009-31 December $2013(n=69)$

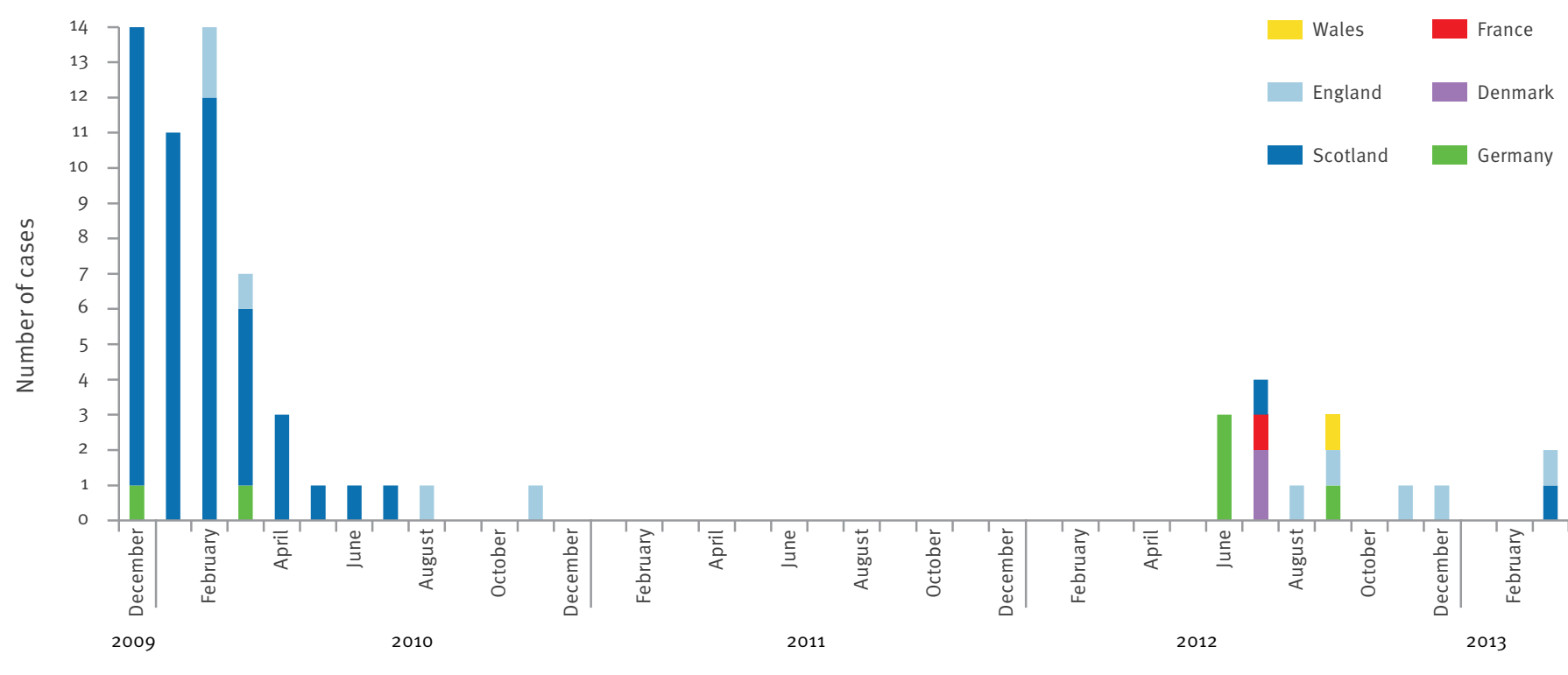

Date (month-year)

Source: $[8-11,14-15]$

outbreak, though the mode of abuse was not well documented in most reports. Of the 47 confirmed cases of anthrax in drug users in Scotland, only two denied injecting at all, lacked visible injection sites and reported using heroin only by smoking. One of those cases developed systemic anthrax. The clinical presentation of the latter two was not described in detail in the HPS report [8]. The report however, describes a number of anthrax cases that were admitted with advanced systemic infection; some without any history of injecting heroin but with a history of taking heroin by other routes, principally smoking, leading to the conclusion that there is a potential risk for systemic disease caused by snorting or smoking heroin contaminated with $B$. anthracis [8].

A case-control study investigating risk factors among 82 confirmed and probable cases in the Scottish outbreak of 2009-2010 found increased risk of injectional anthrax to be associated with longer injecting history (adjusted odds ratio (AOR), 2.43; 95\% confidence interval $(\mathrm{Cl}), 1.31-4.52)$, receiving opioid substitution therapy (AOR, 2.74; 95\% Cl, 1.40-5.37) and alcohol abuse $(P=0.09 ; A O R, 1.77 ; 95 \% \mathrm{Cl}, 0.91-3.47)$. Smoking heroin was associated with lower risk of infection individuals who only smoked heroin in the past month were less likely to be a case (AOR 0.42 ; 95\% Cl, 0.20o.86). The authors did not find an association between sharing injecting equipment and anthrax infection, aligned with the hypothesis that the heroin itself was the source of contamination and explaining the higher risk among patients with longer injecting history [12].
During 2011 there were no reports on new injectional anthrax cases. Moreover, a retrospective serological pilot study in two German regions conducted in 2011 failed to discover additional anthrax cases among 288 heroin users [27]. However, since June 2012 new cases have reemerged in Europe, including Denmark, France,

\section{TABLE 2}

Injectional anthrax case categories [8]

A drug user with a clinical syndrome compatible with anthrax ${ }^{a}$ AND:

\begin{tabular}{|l|l|}
\hline & $\begin{array}{l}\text { One or more of: } \\
\text { - Growth of Bacillus anthracis from a clinical isolate } \\
\text { confirmed by the reference laboratory } \\
\text { Evidence of B. anthracis DNA by PCR on multiple } \\
\text { target genes } \\
\text { Confirmed } \\
\text { case } \\
\text { Demonstration of B. anthracis in a clinical } \\
\text { - Serology with seroconversion on paired specimens } \\
\text { - Demonstration of specific anthrax toxin in blood }\end{array}$ \\
\hline $\begin{array}{l}\text { Probable } \\
\text { case }\end{array}$ & $\begin{array}{l}\text { Gram-positive bacilli identified or bacterial colony } \\
\text { growth (phenotypically resembling B. anthracis) } \\
\text { from either a tissue specimen / swab of lesion or } \\
\text { fluid/collection or blood culture }\end{array}$ \\
\hline $\begin{array}{l}\text { Possible } \\
\text { case }\end{array}$ & $\begin{array}{l}\text { Symptomatic individuals with an epidemiological link } \\
\text { to a known confirmed or probable case }\end{array}$ \\
a Wide-ranging case presentation of anthrax occurred in heroin \\
users. All possible presentations of anthrax need to be \\
considered in anyone with a history of recent heroin use by any \\
route: injection related soft tissue infections (chief presentation \\
of injectional anthrax), severe sepsis and meningitis. Also \\
potentially possible are inhalational and cutaneous anthrax from \\
snorting or handling contaminated heroin [8].
\end{tabular}


Germany, and the United Kingdom (UK): England, Scotland, and Wales [9-11]. So far, 15 confirmed cases were reported, among them seven fatal, contributing to a $47 \%$ case fatality rate (Table 1 , Figure 1 ). Less than half of case reports included epidemiological data such as age and sex, of those who did, the age range varied from 27 to 55 years $[10,14,15,25,26]$.

To date, no person-to-person transmission was documented in injectional anthrax cases. There seems to be no risk for health workers or for the general population $[4,6,8,10,14-26]$.

\section{Source of infection}

Since anthrax is rare in Europe and all cases occurred in drug users, it was assumed that the 2009-2010 outbreak was caused by a contaminated batch of heroin, even though microbiological analysis of heroin samples from a variety of sources in Europe failed to detect contamination with anthrax spores $[8,25]$. The possibility of deliberate contamination was not eliminated but seemed unlikely due to the affected population [8]. Several recent studies $[13-15,27,28]$ have conducted molecular analysis of $B$. anthracis isolates from the first reported case in Norway in 2000 , from cases during the 2009-2010 outbreak and from cases in Denmark and Germany from the 2012-2013 outbreak. All isolates were closely related and it was concluded that they belong to the same $B$. anthracis strain despite small observed variations [13-15, 27]. This single anthrax strain was closely related to strains originating in Turkey. The findings suggested that the outbreak in Europe possibly derived from a single common source which was contaminated before the heroin was distributed. Accidental contamination with anthrax spores might have occurred along the drug manufacturing and trafficking route from soil, through an animal derived cutting agent (used to dilute the illicit drug) or animal hides used to smuggle heroin into Europe [13]. This is compatible with the forensic investigation findings of the 2009-2010 outbreak in the UK which estimated that 80 to $90 \%$ of heroin reaching the UK is supplied via criminal networks in Turkey and is being processed before trafficking $[8,10]$. Thus all analysed cases may be traced back to a single source of contamination that might be still circulating in Europe [27].

\section{Clinical presentation}

Clinical data from 13 case reports describing 18 confirmed cases is summarised in Table $3[4,6,14-23,25]$ and presents several common features.

\section{Injection site}

Sixteen of the 18 published cases presented with severe soft tissue infection originating in the injection site one to ten days post injection $[4,6,14-20,22,25]$. Among laboratory-confirmed cases in Scotland from the 2009-2010 outbreak, whose symptoms were recorded as present or absent, 39 of 42 cases presented with skin or soft tissue involvement [8]. The estimated median time from the presumed 'culprit' injection to hospitalisation was three days [8]. Signs of skin infection varied among patients. The most consistent presenting sign, appearing in all 16 cases diagnosed with soft tissue infection, was substantial swelling or edema, at times defined as disproportionate to the skin lesion or extent of pain described. Erythema and pain were not essential features at presentation. Some reports described blistering or necrosis of skin (Table 3). Three cases were diagnosed initially with compartment syndrome or necrotising fasciitis $[6,17,20]$.

None of the published cases showed the typical signs of cutaneous anthrax - a black crusted painless lesion, known as eschar $[4,6,14-23,25]$. According to the HPS report, only one confirmed case presented with eschar formation [8].

When documented, imaging and soft tissue exploration revealed edematous muscle and subcutaneous tissue (with or without necrosis) and serous discharge with no localised collection, pus or abscess formation [4,17-20,25]. Fever, leukocytosis and elevated C-reactive protein (CRP) were not consistent features of patients presenting with soft tissue infection $[4,8,15,16,20,24,25]$. The minority of reports provided patients' history of past blood-borne infections or immunological status including HIV status (Table 3 and HPS report [8]), conditions which may also have contributed to the diminished inflammatory response.

\section{Gastrointestinal, respiratory and neurological symptoms}

According to the HPS report, 22 of 40 laboratory-confirmed cases in Scotland described non-specific gastrointestinal symptoms such as nausea, vomiting and abdominal pain [8]. There are two reports on an unusual presentation of acute abdominal pain and peritonitis due to groin heroin injection [21,25].

Presenting with respiratory symptoms such as dyspnoea and pleuritic chest pain was extremely rare and was attributed to disseminated disease and sepsis in two cases, according to the HPS report [8]. Nausea and dyspnoea were also evident in one patient from Germany during the 2012-2013 outbreak [15].

Fourteen of 42 Scottish laboratory-confirmed cases reported neurological symptoms of variable degree [8]. A small number of injectional anthrax patients presented with signs of progressive systemic infection and meningitis. This was described in one case report of a patient with prolonged headache, confusion and coma [23]. This case and four more cases were diagnosed with intracranial or subarachnoid haemorrhage [8], and from available data, at least four of these five cases deteriorated rapidly and later died [23,24].

Clinical information about cases diagnosed since June 2012, is limited to three published case reports regarding five confirmed cases $[14,15,25]$ (Table 3 ) and a brief 


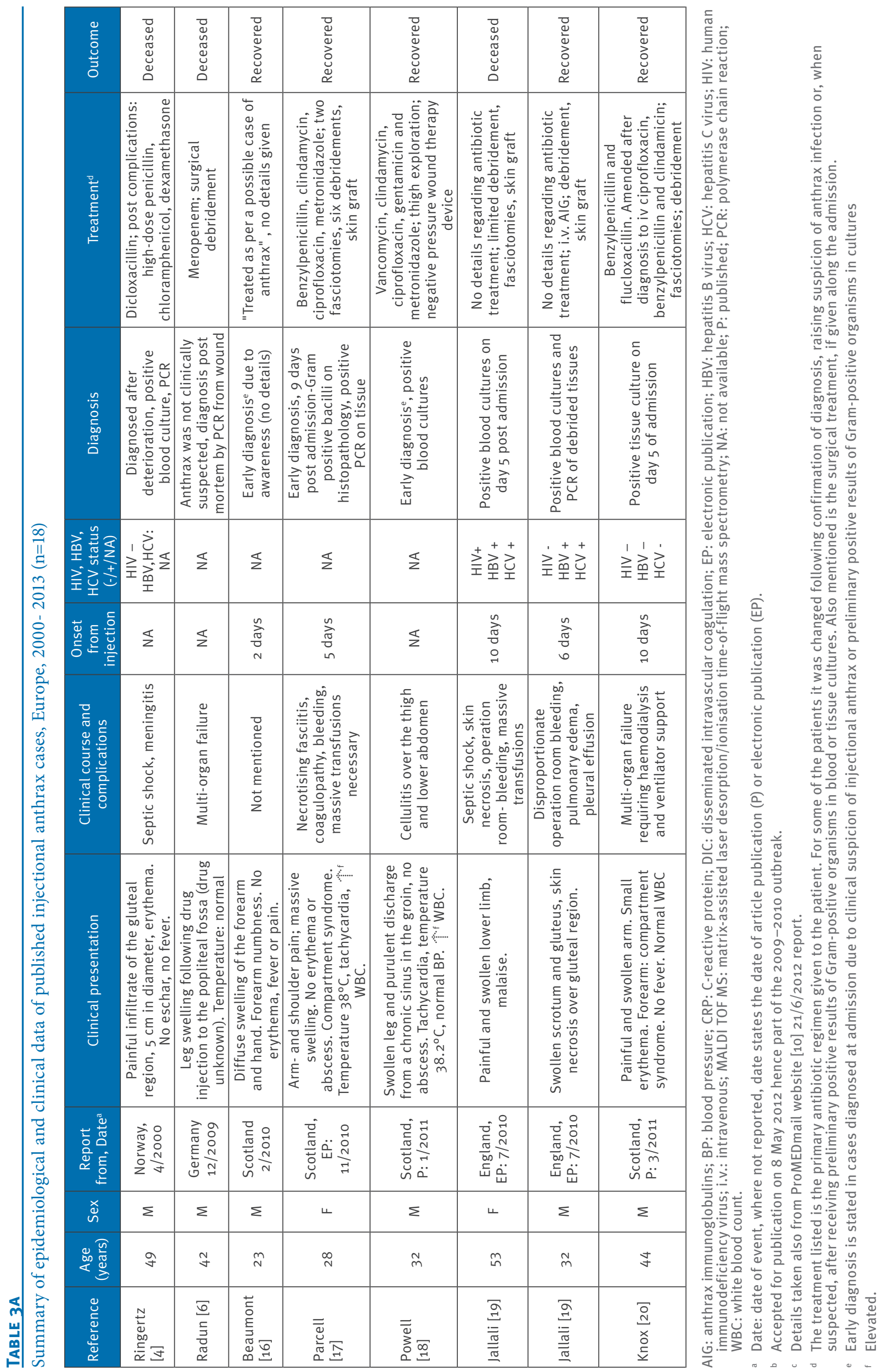




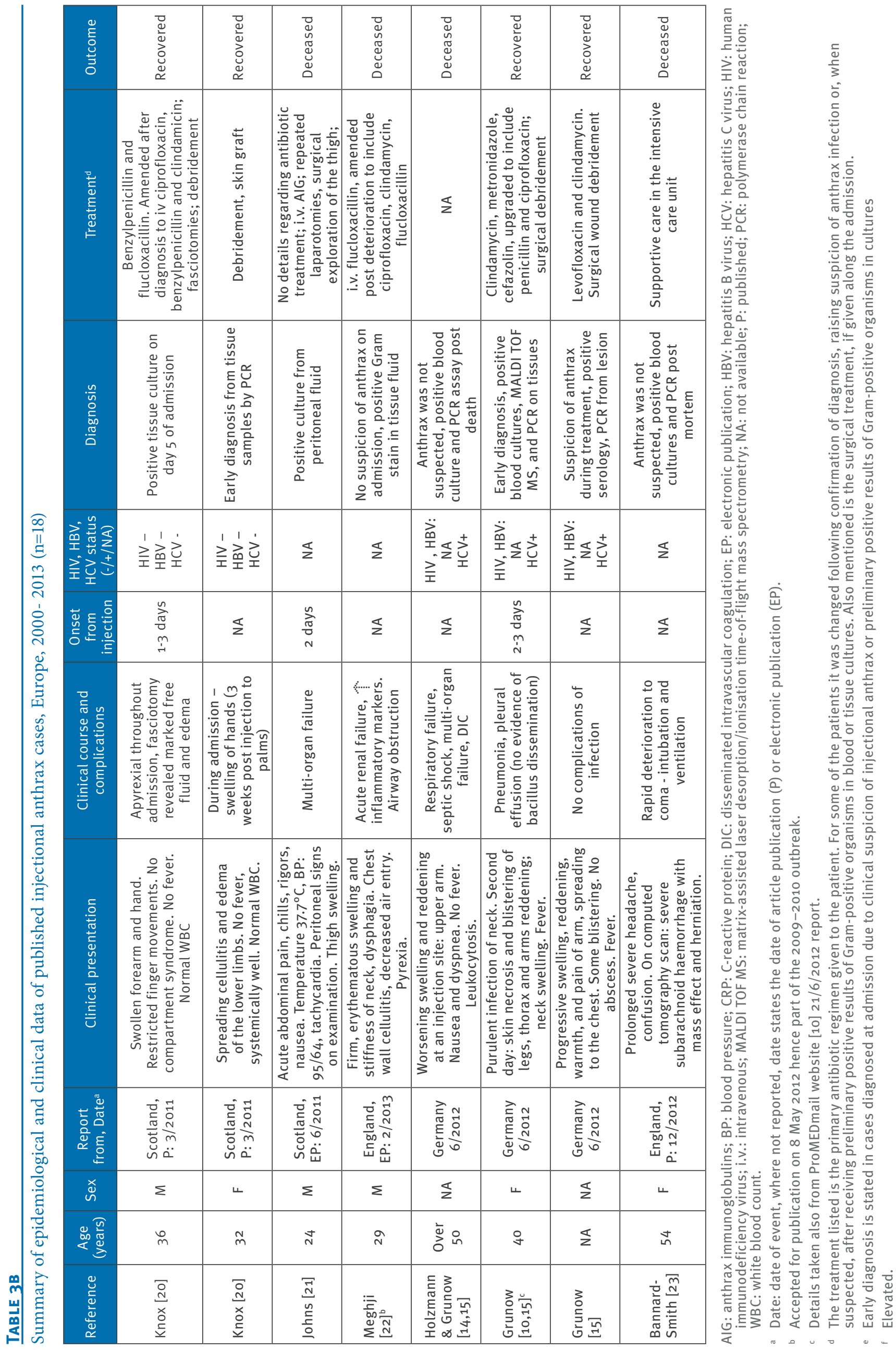




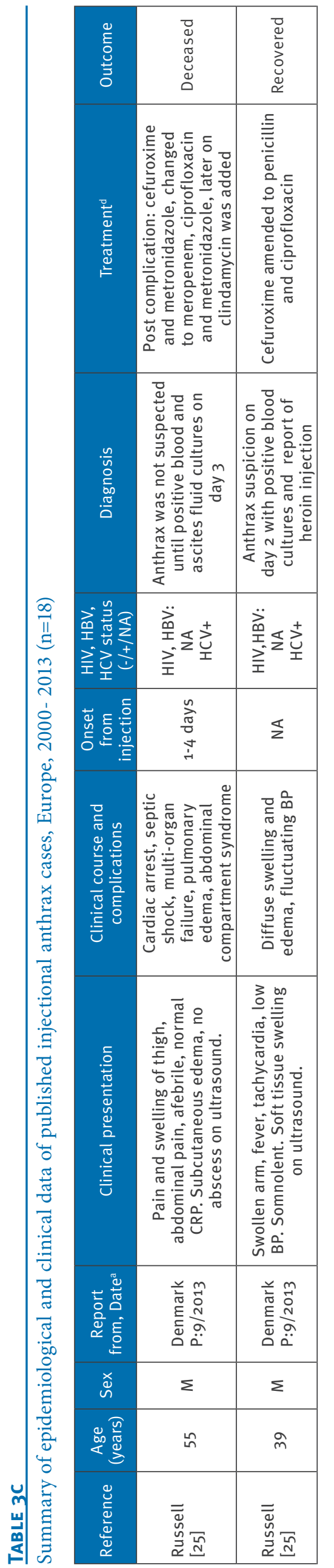

description of the single case diagnosed in France [26]. It appears that the clinical presentation and course were similar to those described in the 2009-2010 outbreak $[9-11,14,15,25,26]$ (Table 3).

Clinical course and complications

Among 16 reported cases presenting with soft tissue infection, four patients demonstrated haemodynamic stability $[16,18,20]$, one of them despite evidence of $B$. anthracis bacteraemia [18]. However, nine patients showed progressive soft tissue infection and systemic complications such as coagulopathy, rapid deterioration to septic shock, toxaemia and multi-organ failure $[4,6,14,15,17,19,20,22,25]$. An important complication occurring intra- or post debridement procedures of soft tissue infections was disproportionate bleeding and oozing (at times, despite correction of coagulopathy) requiring massive transfusions [8]. This was documented in three of the reported cases $[17,19]$.

Patients lacking signs of soft tissue infection, who presented with other signs of systemic infection, meningitis or peritonitis were usually misdiagnosed and rapidly deteriorated due to lack of appropriate treatment $[21,23,24]$ (Table 3).

Following admission, two of the reported cases developed pleural effusions, one associated with pulmonary edema [19] and the other associated with pneumonia [15]. In both cases there was no evidence of $B$. anthracis in the pleural fluid cultures. Besides these two cases, diagnosed outside of Scotland, the HPS report found that a small pleural effusion which did not cause symptoms was detected in ten of 41 patients reported. In some cases anthrax bacilli were recovered from respiratory samples, either from pleural fluid or in two cases from bronchial tissues or exudate. The HPS report states this may be an evidence of smoking or snorting contaminated heroin [8]. Complications are presented in Table 3.

\section{Diagnosis, management and outcome}

Diagnosis of injectional anthrax was based on traditional microbiological methods as Gram stain and cultures of tissue, blood, peritoneal fluid or cerebrospinal fluid (CSF) and by polymerase chain reaction (PCR). Evidence of scanty pus cells was a common finding in tissue histopathology $[4,6,14-23]$.

In the first cases from Denmark and Germany in 2012, a matrix-assisted laser desorption/ionisation time-offlight (MALDI-TOF) mass spectrometry method or serology testing for antibodies to the $B$. anthracis protective antigen were also utilised $[14,15,25,26]$.

Patient management was inconsistent. When reported, most cases presenting with soft tissue infection were treated with supportive treatment and antibiotic regimen with or without surgical intervention. The antibiotic regimen varied among cases: anthrax infection was not clinically suspected in eight patients and treatment covered other, more common, causes of severe 
soft tissue infections $[4,6,15,20,22,25]$. This is possibly due to these patients being among the first injectional anthrax cases in different countries. In six of those cases, antibiotic regimens were amended upon clinical suspicion or after preliminary results have suggested anthrax infection $[15,20,22,25]$. The diagnosis of anthrax infection at presentation was raised in three patients, who were treated with a combination of four or five antibiotics covering both $B$. anthracis infection and more common pathogens causing soft tissue infections. These three patients were part of the 2009-2010 outbreak in Scotland, hence early detection might have been due to clinicians' awareness of the ongoing outbreak $[17,18,20]$ (Table 3). Surgical procedures were reported in ten of 15 cases presenting with soft tissue infection $[6,15,17-20]$ and included explorative surgery, fasciotomy and tissue debridement as well as occasional skin grafting. Four patients required multiple debridement procedures $[15,17,20]$ (Table 3).

In addition, few patients were treated with intravenous anthrax immunoglobulin (i.v. AIG) provided by the United States' Centers for Disease Control and Prevention (CDC) as an investigational new drug (IND). According to the HPS report on the 2009-2010 outbreak, of the 119 Scottish cases, 14 were treated with i.v. AIG [8]. Outside of Scotland, only one case report, from England, stated i.v. AIG usage [19]. Detailed information regarding these patients is lacking, though according to the CDC guidelines for anthrax post-exposure prophylaxis and treatment, of the 15 injectional anthrax cases treated with i.v. AIG, 10 survived and all cases appeared to tolerate the antitoxin [29].

As described, in many cases anthrax was not suspected or was diagnosed with delay. When reported, delay ranged from three to 12 days post admission to hospital $[6,19,25]$ or a first visit to a clinic [4]. This probably contributed to the adverse outcome of eight fatalities among 18 published cases [4,6,14,15,19,21-23,25]. Mortality was higher among the 15 cases arising since June 2012 in comparison to the 2009-2010 outbreak (Table 1). One contributing factor to the difference in mortality rate might have been enhanced awareness and knowledge of injectional anthrax among care givers during the Scottish outbreak leading to earlier adequate treatment.

\section{Discussion}

Injecting drug users (IDUs) are at higher risk of developing diverse forms of infections, among those, soft tissue infection is a well-known complication of parenteral drug use, though anthrax infection of injection sites was considered very rare before the 2009-2010 injectional anthrax outbreak [30,31]. Hope et al. have estimated the differences in rates of severe infections among IDUs in Europe, between 2000-2009, caused by four spore-forming bacteria that have been associated with contaminated heroin - Clostridium botulinum, $C$. tetani, C. novyi, and B. anthracis. They identified 367 infections over the 10-year period. Of these cases,
300 occurred in the UK; only 13 of those were caused by $B$. anthracis. These 300 infections led to an overall rate of 1.9 to 2.1 infections per 1,000 IDUs over 10 years (among those $0.083-0.09$ anthrax infections per 1,000 IDUs). The rates of infection with spore-forming bacteria among IDUs in other European countries (Germany, Greece, Italy, the Netherlands and Norway) were much lower than those in the UK, with the exception of a higher infection rate in Ireland (3.9-6.6 infections/1,000 IDUs/10 years) [32].

Thus, although the 2009-2010 injectional anthrax outbreak has constituted the largest cluster of severe bacterial infection among IDUs in Scotland in a decade, with a rate of 1.96 confirmed anthrax infections per 1,000 heroin users in Scotland [8], overall $B$. anthracis is an uncommon cause of soft tissue infection among IDUs and other more common pathogens as staphylococci, streptococci and anaerobes [31] must be considered first in the differential diagnosis and management of patients. Nevertheless, injectional anthrax should be considered in the differential diagnosis of a heroin user presenting with severe soft tissue infection at an injection site, with a progressive course, that does not respond to customary antimicrobial agents aimed to treat most common pathogens causing soft tissue infections, especially in the context of epidemiological link to other injectional anthrax cases in the area.

Another unprecedented outbreak among injecting heroin users took place predominantly in Scotland between April and August 2000. This was mainly attributed to $C$. novyi type $A$ infection, manifesting with a very similar presentation to injectional anthrax i.e. marked swelling and pain at the intramuscular injection site and/or multi-organ failure, presenting within 10 days of injection. As opposed to injectional anthrax infection, this outbreak had a higher case-fatality rate, of $87 \%$ ( 20 of 23 definite cases), and a higher number of cases had necrotising fasciitis (15/23) and pleural effusion $(13 / 23)$. One of its characteristic features was a leukaemoid reaction - a markedly raised white cell count with left shift and a median white cell count of $60 X_{109} / \mathrm{L}$ (normal range $~ 3.54-9.06 \times 109 / \mathrm{L}$ ), which is not a common feature of injectional anthrax [33].

Both C. novyi and B. anthracis outbreaks have occurred in clusters, which were attributed to specific batches of contaminated heroin [34], both outbreaks necessitated comprehensive measures of containment.

During the 2009-2010 outbreak informative materials were distributed to drug addicts, recommending drug users to stop using heroin and to ask for medical help in case of symptoms. Clinicians were alerted and the police reinforced its attempts to interrupt the heroin distribution networks [8]. The reoccurrence of 15 injectional anthrax cases since June 2012, most likely caused by the same $B$. anthracis strain as the 2009-2010 outbreak $[13-15,25,27]$ affirmed that contaminated heroin probably still circulates in at least 
Comparison of clinical presentation, clinical course, diagnosis, treatment and outcome of cutaneous versus injectional anthrax cases, Europe, 2000-2013

\begin{tabular}{|c|c|c|}
\hline & Cutaneous anthrax & Injectional anthrax ${ }^{a}$ \\
\hline Classical presentation & $\begin{array}{l}\text { Papule progresses to a vesicle and to a black } \\
\text { eschar. Painless lesion without purulence }+/- \\
\text { marked non-pitting edema. Numerous bacilli, } \\
\text { paucity of leukocytes on staining }[1,2] \text {. }\end{array}$ & $\begin{array}{l}\text { Soft tissue infection with marked edema, painless at times, } \\
\text { without pus, scarce leukocytes on staining. No eschar. } \\
\text { Changes are attributed to bacterial virulence factors including } \\
\text { edema and lethal toxins (Table } 3 \text { ). }\end{array}$ \\
\hline Mortality rate & $\begin{array}{l}\ll 1 \% \text { when treated, } \\
10-20 \% \text { without treatment }[1,2] \text {. }\end{array}$ & $37 \%$ (26/70 confirmed cases), higher rate of septicaemia (Table 1$).$ \\
\hline Diagnosis & $\begin{array}{l}\text { Gram stain and culture from lesion usually } \\
\text { sufficient }[1,2]^{b}\end{array}$ & $\begin{array}{l}\text { Mainly Gram stain, culture and PCR confirmation from blood, } \\
\text { tissue, pus or other body fluid. Other methods included silver } \\
\text { and immunohistochemical staining, serum samples for toxin } \\
\text { levels, MALDI TOF MS and serology testing (Table 3). }\end{array}$ \\
\hline Antibiotic regimen & $\begin{array}{l}\text { Naturally acquired cutaneous anthrax: } \\
\text { For localised, uncomplicated cases oral } \\
\text { ciprofloxacin or doxycycline for seven to } 10 \\
\text { days. For severe cases with signs of systemic } \\
\text { involvement, extensive edema, or lesions of } \\
\text { head and neck - i.v. therapy for } 7-10 \text { days } \\
{[29,35] \text {. }}\end{array}$ & $\begin{array}{l}\text { Soft tissue infection - i.v. combination of five antimicrobial } \\
\text { agents to cover both } B \text {. anthracis, and other more common } \\
\text { causes of severe soft tissue infections: ciprofloxacin, } \\
\text { clindamycin, penicillin, flucloxacillin, metronidazole. } \\
\text { Systemic anthrax without soft tissue infection - therapy as } \\
\text { inhalational anthrax with potential CNS involvement: i.v. } \\
\text { ciprofloxacin and clindamycin with at least one other active } \\
\text { drug against } B \text {. anthracis - penicillin or vancomycin (in patients } \\
\text { allergic to penicillin) [36].c }\end{array}$ \\
\hline Additional treatment & No information. & $\begin{array}{l}\text { Exploration surgeries and tissue debridement for the removal } \\
\text { of toxin reserve and devitalised tissue. Fasciotomy for } \\
\text { compartment syndrome. } \\
\text { i.v. AIG when indicated for confirmed or probable case (positive } \\
\text { Gram stain) [36]. }\end{array}$ \\
\hline
\end{tabular}

AIG: anthrax immunoglobulin; CNS: central nervous system; i.v.: intravenous; MALDI TOF MS - Matrix-assisted laser desorption/ionisation time-of-flight mass spectrometry.

a More comparable with systemic anthrax regarding fatality rate, diagnosis and antimicrobial treatment.

b Diagnostic procedures should preferably be performed prior to initiation of antibiotics, as vesicular fluid and dermal tissue are quickly sterilized after initiation of antibiotics [1].

Other agents with anti-anthrax activity include rifampicin, imipemem, meropenem, chloramphenicol and gentamicin. For the duration of therapy - refer to text. Ciprofloxacin is the preferred choice over doxycycline in cases of severe disease. Clindamycin is included for its bacterial toxin synthesis inhibition ability and the third antimicrobial drug is included for its adequate activity against $B$. anthracis and CNS penetrance properties $[29,35,36]$.

six European countries and further appearance of new injectional anthrax cases might be expected.

Injectional anthrax presents a challenge for physicians often due to lack of evident case clusters, unfamiliar clinical presentation and severe course of disease. Unlike cutaneous anthrax, injectional anthrax is typically a systemic infection with high mortality rate (Table 4). This may be attributed to the deeper and greater inoculation of spores, higher rates of septicaemia, delayed diagnosis and to factors specific to drug addicts including delayed medical consultation, malnutrition, presence of concomitant diseases such as HIV infection and defective immune response. The weight of these contributing factors could not be assessed in the absence of a detailed database and a lack of a control group exposed to the pathogen through the same route.

The predominantly systemic nature of injectional anthrax requires different management than cutaneous anthrax. In cases of naturally occurring cutaneous anthrax, oral antibiotic treatment with fluoroquinolones (ciprofloxacin, levofloxacin, and moxiflloxacin) or doxycycline is usually sufficient $[29,35]$. However, the progressive clinical course of injectional anthrax, frequent systemic involvement and high fatality rate necessitates early and aggressive management. Most reported cases with soft tissue infection required surgical procedures such as debridement or fasciotomy in cases of compartment syndrome. These interventions were made in addition to i.v. antibiotic therapy, adjuvant treatment with i.v. AIG in some cases and supportive critical care management $[6,15,17-20]$.

In March 2010 the HPS published interim clinical guidance for the management of suspected anthrax in drug users [36]. In accordance to it, the appropriate management of cases with soft tissue infection should include i.v. application of a combination of antimicrobial agents. As for the duration of treatment, the guidance suggest reviewing antimicrobial therapy after ten 
to 14 days of i.v. therapy, and either continuation of therapy, modification of agent or its route of administration, or discontinuation of therapy, depending on the clinical course of the individual patient. When therapy has ceased, patients must be monitored closely for worsening of symptoms necessitating renewal of therapy and re-evaluation of the need for further surgical debridement [36].

According to the US CDC guidelines for anthrax postexposure prophylaxis and treatment, systemic illness cases that were exposed to aerosolised spores should be treated for 60 days due to the potential for delayed germination of $B$. anthracis spores $[29,35]$. Inhalational exposure to aerosolised spores should be considered in cases of smoking or snorting of contaminated heroin.

Complementary treatment with corticosteroids may be beneficial for patients with edema, especially of the head or neck, with evidence of anthrax meningitis or of vasopressor-resistant shock [29].

Due to insufficient clinical data there are no general recommendations for the use of i.v. AIG for the treatment of severe anthrax infections. The US CDC offers AIG under emergency IND protocol on a patient by patient basis $[29,35]$. The HPS interim clinical guidance recommends the consideration of i.v. AIG if the patient fits the clinical definition and is a confirmed or a probable case based on a Gram stain demonstrating Grampositive bacilli [36].

The main constraint of this review arises from the incomplete information, a limited number of case reports and the variable degree of clinical description that do not allow additional analysis or prognostic indicators assessment regarding clinical presentation and recommended management. However, this review of injectional anthrax cases aspires to serve as a source of knowledge on this recently described and distinctive infection, in order to encourage early recognition, diagnosis and management of future cases and allow further evaluation of diagnostic methods and management of this important pathogen.

\section{Conclusion}

The erratic emergence and severe clinical course of injectional anthrax present a challenge for clinicians. The optimal management of injectional anthrax necessitates a high index of suspicion and prompt treatment. Clinicians should be extra vigilant when examining a heroin user presenting with either severe soft tissue infection at an injection site, signs of severe sepsis or meningitis with or without evidence of soft tissue infection, evidence of intracranial bleeding on a computed tomography scan or symptoms of inhalational anthrax. It is important to be aware of the progressive clinical course of disease. When suspected, diagnostic tests should be performed and appropriate antibiotic treatment be commenced promptly along with surgical debridement and critical care management when indicated.

Conflict of interest

None declared

Authors' contributions

Tamar Berger contributed to the literature search, data collection, analysis and interpretation and writing of the first draft.

Adi Avniel Aran and Michael Kassirer contributed to the data interpretation and writing of the first draft.

\section{References}

1. Martin GJ, Friedlander AM. Bacillus anthracis (Anthrax). In: Mandell GL, Bennett JE, Dolin R, editors. Mandell, Douglas, and Bennett's Principles and Practice of Infectious Diseases, 7th ed. Philadelphia: Elsevier Inc. 2010. Chapter 208. p. 27152725. http://dx.doi.org/10.1016/B978-0-443-06839-3.00208-3

2. Purcell BK, Worsham PL, Friedlander AM. Anthrax. In: Dembek ZF, editor. Medical Aspects of Biological Warfare. Washington, DC: Office of the Surgeon General, US Army Medical Department Center and School; Borden Institute, Walter Reed Army Medical Center; 2007. p. 69-90.

3. European Centre for Disease Prevention and Control (ECDC). Annual Epidemiological Report 2011. Reporting on 2009 surveillance data and 2010 epidemic intelligence data. Stockholm: ECDC; 2011. Available from: http://www.ecdc. europa.eu/en/publications/publications/1111_sur_annual epidemiological_report_on_communicable_diseases_in_ europe.pdf

4. Ringertz SH, Høiby EA, Jensenius M, Maehlen J, Caugant DA, Myklebust A, et al. Injectional anthrax in a heroin skin-popper. Lancet. 2000; 356(9241):1574-5. http://dx.doi.org/10.1016/ S0140-6736(00)03133-0

5. Ramsay CN, Stirling A, Smith J, Hawkins G, Brooks T, Hood J, et al. An outbreak of infection with Bacillus anthracis in injecting drug users in Scotland. Euro Surveill. 2010;15(2): pii= 19465.

6. Radun D, Bernard H, Altmann M, Schöneberg I, Bochat V, van Treeck U, et al. Preliminary case report of fatal anthrax in an injecting drug user in North-Rhine-Westphalia, Germany, December 2009. Euro Surveill. 2010;15(2): pii=19464.

7. Christie B. Heroin contaminated with anthrax has killed 11 people. BMJ. 2010;340:c937. http://dx.doi.org/10.1136/bmj. c937

8. Health Protection Scotland (HPS). National Anthrax Outbreak Control Team: An outbreak of anthrax among drug users in Scotland, December 2009 to December 2010. Glasgow: HPS; 2011.

9. Public Health England website - Health Protection topics Anthrax: Information on 2012 outbreak. [Accessed 26 January 2014]. Available from: http://www.hpa.org.uk/Topics/ InfectiousDiseases/InfectionsAZ/Anthrax/

10. ProMED-mail. [Accessed 26 Jan 2014]. Available from: http:// www.promedmail.org/

11. European Centre for Disease Prevention and Control (ECDC). [Accessed 26 Jan 2014]. Available from: http://www.ecdc. europa.eu/en/Pages/home.aspx

12. Palmateer NE, Ramsay CN, Browning L, Goldberg DJ, Hutchinson SJ. Anthrax infection among heroin users in Scotland during 2009-2010: a case-control study by linkage to a national drug treatment database. Clin Infect Dis. 2012;55(5):706-10. http://dx.doi.org/10.1093/cid/cis511

13. Price EP, Seymour ML, Sarovich DS, Latham J, Wolken SR, Mason J, et al. Molecular epidemiologic investigation of an anthrax outbreak among heroin users, Europe. Emerg Infect Dis. 2012;18(8):1307-13. http://dx.doi.org/10.3201/ eid1808.111343

14. Holzmann T, Frangoulidis D, Simon M, Noll P, Schmoldt S, Hanczaruk $M$, et al. Fatal anthrax infection in a heroin user from southern Germany, June 2012. Euro Surveill. 2012;17(26): $\mathrm{pii}=20204$

15. Grunow R, Verbeek L, Jacob D, Holzmann T, Birkenfeld G, Wiens $D$, et al. Injection anthrax-a new outbreak in heroin users. Dtsch Arztebl Int. 2012;109(49):843-8. 
16. Beaumont G. Anthrax in a Scottish intravenous drug user. J Forensic Leg Med. 2010;17(8):443-5. http://dx.doi. org/10.1016/j.jflm.2010.09.008

17. Parcell BJ, Wilmshurst AD, France AJ, Motta L, Brooks T, Olver WJ. Injection anthrax causing compartment syndrome and necrotising fasciitis. J Clin Pathol. 2011;64(1):95-6. http:// dx.doi.org/10.1136/jcp.2010.082586

18. Powell AG, Crozier JE, Hodgson H, Galloway DJ. A case of septicaemic anthrax in an intravenous drug user. BMC Infect Dis. 2011;11:21. http://dx.doi.org/10.1186/1471-2334-11-21

19. Jallali N, Hettiaratchy S, Gordon AC, Jain A. The surgical management of injectional anthrax. J Plast Reconstr Aesthet Surg. 2011 Feb; 64(2):276-7. http://dx.doi.org/10.1016/j. bjps.2010.06.003

20. Knox D, Murray G, Millar M, Hamilton D, Connor M, Ferdinand $\mathrm{RD}$, et al. Subcutaneous anthrax in three intravenous drug users. J Bone Joint Surg Br. 2011;93(3):414-7. http://dx.doi. org/10.1302/0301-620X.93B3.25976

21. Johns N, Cooper D, Terrace J. An unusual case of peritonitis in an intravenous drug user. Gastroenterology. 2011;141(2):4356, 780-1. http://dx.doi.org/10.1053/j.gastro.2011.02.076

22. Meghji S, Judd $\mathrm{O}$, Carr E. Fatal cutaneous anthrax in a heroin user. J Laryngol Otol. 2013;127(4):423-5. http://dx.doi. org/10.1017/So022215112003210

23. Bannard-Smith J, Carroll I, Nichani R, Sharma R. Anthrax infection in an intravenous drug user. Intensive Care Med. 2013;39(3):530. http://dx.doi.org/10.1007/s00134-012-2772-0

24. Booth MG, Hood J, Brooks TJ, Hart A. Anthrax infection in drug users. Lancet 2011;375(9723):1345-1346. http://dx.doi. org/10.1016/S0140-6736(10)60573-9

25. Russell L, Pedersen M, Jensen AV, Sřes LM, Hansen AB. Two anthrax cases with soft tissue infection, severe oedema and sepsis in Danish heroin users. BMC Infect Dis. 2013;13:408. http://dx.doi.org/10.1186/1471-2334-13-408

26. European Centre for Disease Prevention and Control (ECDC). Risk assessment: Anthrax cases among injecting drug users Germany, June-July 2012 - Update, 13 July 2012. [Accessed 6 Feb 2013]. Available from: http://ecdc.europa.eu/en/ publications/publications/rapid-risk-assessent-anthrax-idusjuly-13.pdf

27. Grunow R, Klee SR, Beyer W, George M, Grunow D, Barduhn A, et al. Anthrax among heroin users in Europe possibly caused by same Bacillus anthracis strain since 2000 . Euro Surveill. 2013 Mar 28;18(13): pii=20437

28. Rückert C, Licht K, Kalinowski J, Espírito Santo C, Antwerpen $M$, Hanczaruk $M$ et al. Draft genome sequence of Bacillus anthracis UR-1, isolated from a German heroin user. J Bacteriol. 2012;194(21):5997-8. http://dx.doi.org/10.1128/JB.01410-12

29. Hendricks KA, Wright ME, Shadomy SV, Bradley JS, Morrow MG, Pavia AT et al. Centers for disease control and prevention expert panel meetings on prevention and treatment of anthrax in adults. Emerg Infect Dis. 2014;20(2). http://dx.doi. org/10.3201/eid2002.130687

30. Kaushik KS, Kapila K, Praharaj AK. Shooting up: the interface of microbial infections and drug abuse. J Med Microbiol. 2011;60 (Pt 4):408-22. http://dx.doi.org/10.1099/ jmm.0.027540-0

31. Lavender TW, McCarron B. Acute infections in intravenous drug users. Clin Med. 2013;13(5):511-3. http://dx.doi.org/10.7861/ clinmedicine.13-5-511

32. Hope VD, Palmateer N, Wiessing L, Marongiu A, White J, Ncube $F$ et al. A decade of spore-forming bacterial infections among European injecting drug users: pronounced regional variation. Am J Public Health. 2012;102(1):122-5. http://dx.doi. org/10.2105/AJPH.2011.300314

33. McGuigan CC, Penrice GM, Gruer L, Ahmed S, Goldberg $D$, Black $M$ et al. Lethal outbreak of infection with Clostridium novyi type A and other spore-forming organisms in Scottishinjecting drug users. J Med Microbiol. 2002;51(11):971-7.

34. Palmateer NE, Hope VD, Roy K, Marongiu A, White JM, Grant KA et al. Infections with spore-forming bacteria in persons who inject drugs, 2000-2009. Emerg Infect Dis. 2013;19 (1):29-34. http://dx.doi.org/10.3201/eid1901.120044

35. Stern EJ, Uhde KB, Shadomy SV, Messonnier N. Conference Report on Public Health and Clinical Guidelines for Anthrax. Emerg Infect Dis. 2008;14(4). http://dx.doi.org/10.3201/ eid1404.070969

36. Health Protection Scotland (HPS). Interim clinical guidance for the management of suspected anthrax in drug users: version 12.1. [Accessed 5 Feb, 2013]. Available from: http://www.hps. scot.nhs.uk/anthrax/documents/clinical-guidance-for-use-ofanthraximmune-globulin-v12-1-2010-03-19.pdf 